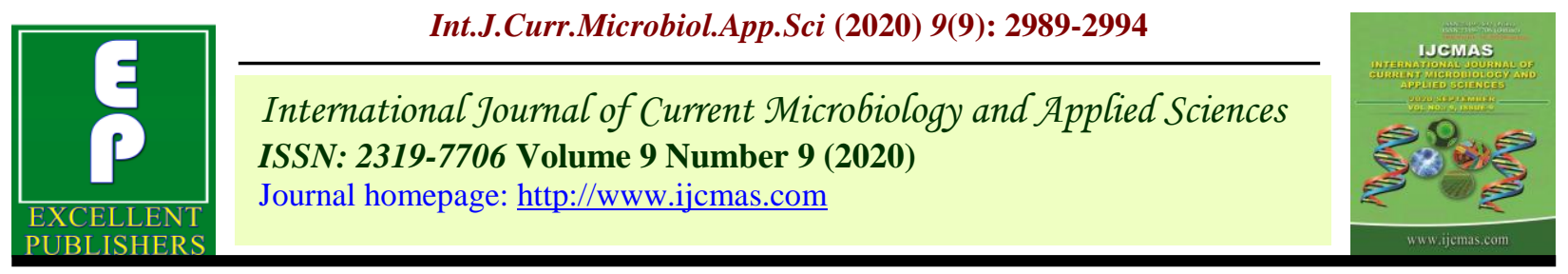

Original Research Article

https://doi.org/10.20546/ijcmas.2020.909.368

\title{
Characterization of Raw Material Powder Extracted at High Temperature from Fluoride Groundwater
}

\author{
Valipenta Narasimhulu ${ }^{1}$, Sudhakar Bansod ${ }^{2 *}$, \\ Lakshmi Srinivasa Rao Kundeti ${ }^{1}$ and Ravindra M. Kumbhare ${ }^{1}$
}

${ }^{1}$ Academy of Scientific and Innovative Research (AcSIR), Ghaziabad-201002, India

${ }^{2}$ Fluoro-Agrochemicals Department, CSIR-Indian Institute of Chemical Technology, Tarnaka, Hyderabad-500007, India

*Corresponding author

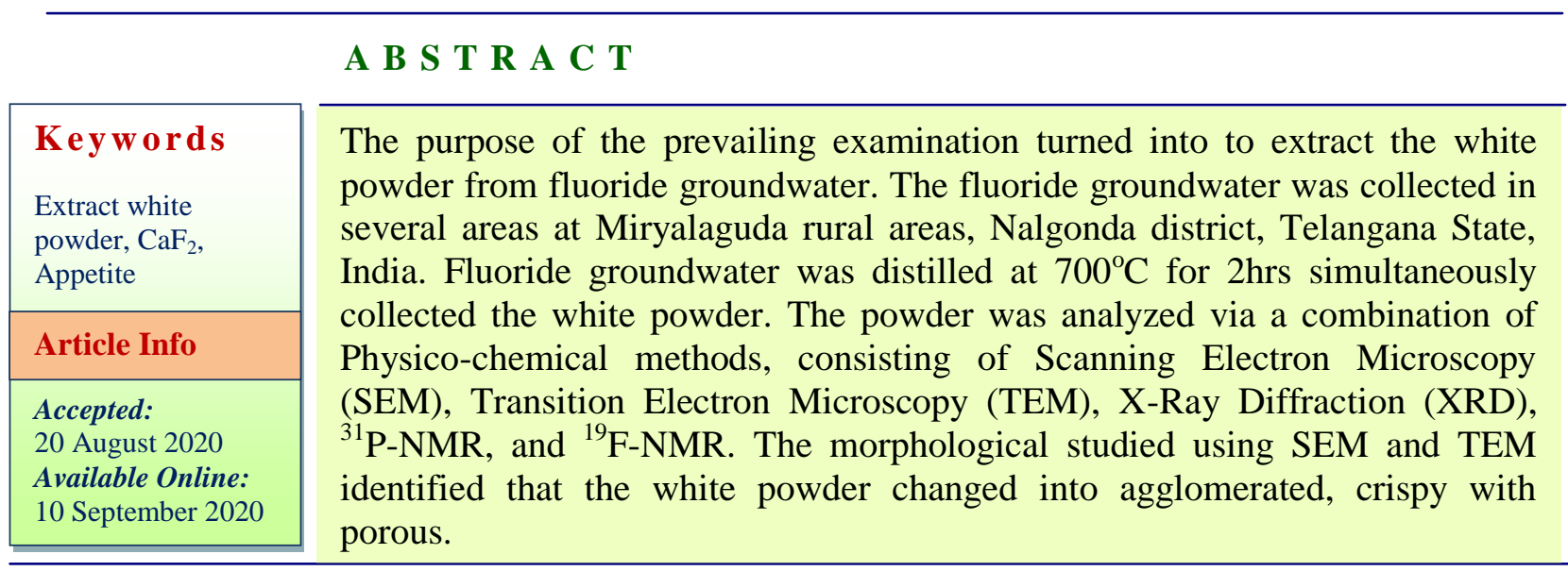

\section{Introduction}

The groundwater is a characteristic of many factors and solubility of fluoride minerals, $\mathrm{pH}$, temperature, ions in the water though fluoride enters the body through drinking water (1). Fluoride is the formation of the bond with metals $\left(\mathrm{CaF}_{2}\right)$ in groundwater, a natural component in the environment fluoride is accessible Fluorite fluorspar, rock phosphate, cryolite, apatite, hydroxylapatite, mica, hornblende fluoride beyond suitable quantities $(0.6$ to $8 \mathrm{mg} / \mathrm{L})$ in groundwater is the main problem in many parts of the arena
(2). Fluorine is the lightest individual from the halogen gathering and one of the greatest responsive of every synthetic factor. It is thusly not found as fluorine in the earth. Fluorine is moreover the most electronegative everything being equal and subsequently, has a solid inclination to assemble a negative rate to frame a monovalent particle, fluoride $\left(\mathrm{F}^{-}\right)$ (3). Fluoride in groundwater is chief trouble in many components of the global. Around two hundred million human beings from 25 countries have fitness risks because of excessive fluoride in groundwater. In India too, there has been a growth within the 
prevalence of dental and skeletal fluorosis with about 62 million humans at hazard because of excessive fluoride concentration in consuming water. Dental fluorosis is endemic in 14 states and 150,000 villages in India with the trouble most reported inside the states of Telangana (4). World Health Organization (WHO) recommends that the fluoride content in drinking water should be in the range of 0.6 to $1.5 \mathrm{mg} / \mathrm{l}$. Fluoride groundwater was distilled and collected the white powder. The raw compounds of inorganic geometrical compounds with properly-defined and controllable morphologies have stimulated enormous attention; due to the fact its miles widely known that the residences of the white powder carefully interrelate with geometrical factors along with morphology, dimensionality, and the scale. Geometrical inorganic compounds were properly-mounted that alkali earth metal (AEM) fluorides, (AEM) phosphate. Under such unique optical houses and instead reasonable bodily characteristics, one may additionally assume excessive peak laser motion. That is why those single AEM fluorides and AEM phosphate doped via a few uncommon-earth trivalent ions regarded gadgets of in-depth investigations from the very start of the final decade of this technology.

\section{Experimental}

\section{Study area}

Nalgonda district in India spread a place of $14,240 \mathrm{~km}$., and the populace is 36.25 lakhs as shown in Fig. 1. The geographically Nalgonda district are sandy and includes granite combined alkali earth metals with fluoride in Nalgonda areas, gift look at the region, Nalgonda division comprises of, Miryalaguda Mandal rural regions Ailapuram, Alagadappa, Annaram, Chillapuram, Chinthapalle, Goguvanigudem, Gudur, Hydlapuram, Kalvapalle, Kistapuram,
Kothaguda, Mulkalkalva, Nandipahad(Rural), Narsimhulaguda, Rayanpalem, Rudraram, Tadkamalla, Takkellapahad, Thungapahad, Venkatadripalem, samples have gathered.

In this study collected fluoride groundwater samples from several Miryalaguda 46 rural areas of Nalgonda district, Telangana state, India. Distilled the collected water, and extracted solid inorganic white powder compounds obtained weight from 50 to 400 $\mathrm{mg}$ per liter of fluoride groundwater. The collected powder as mentioned in the Fig. 2. As we recognize inside India there are three principal seasons within the year like wet (June-September), winter (October-January), and summer season (February-May). Temperatures in India are fairly medium, ranging from at the least $10^{\circ} \mathrm{C}$ in January to a maximum of $48^{\circ} \mathrm{C}$ in May, with a mean annual value of $35^{\circ} \mathrm{C}$. The climate of the area is assessed as semi-arid and suggests annual rainfall is between $300-650 \mathrm{~mm}$. From Fig. 2, it indicates that as the summer season begins the content of fluoride within the water are constantly increases. The dissolution of evaporative salts deposits in arid environments will also be a critical source of fluoride. On the alternative hand, fluoride enrichment of groundwater is less pronounced in humid tropical regions due to excessive rainfall inputs and the diluting impact on groundwater composition (5-7).

\section{Scanning Electron Microscope (SEM) analysis}

The morphology, size, and the homogeneity of the solid raw compounds of fluoride groundwater in Fig. 3, were analyzed by the usage of the Scanning Electron Microscope $(\mathrm{SEM})(8)$. The snapshots found out the sizes were around $700 \mathrm{~nm}-1 \mathrm{um}$. The distinction in response time and the attention of the saturated solutions of precursor lead to prominent sizes of raw materials in white 
powder. Herein, we attempted to get the solid raw materials within the variety of diameter $(100 \mathrm{~nm})$ with homogeneity in a round form and functionally likely raw materials to gain an excessive payload potential(9).

\section{Transmission Electron Microscope (TEM) analysis}

Fig. 4 represents a TEM photograph of raw materials nanoparticles. We found that the coccid morphologies, in general, reflected the size and shape of the central raw materials across nanospheres raw materials that are formed with average sizes of 10-20 $\mathrm{nm}(10)$.

\section{Energy Dispersive X-Ray (EDX) analysis}

Fig. 5 shows the EDX results confirmed that an increase in oxygen abundance to form the appetite and other components.

Fig.1 Fluoride groundwater samples were collected from Miryalaguda rural areas Nalgonda district, Telangana, India
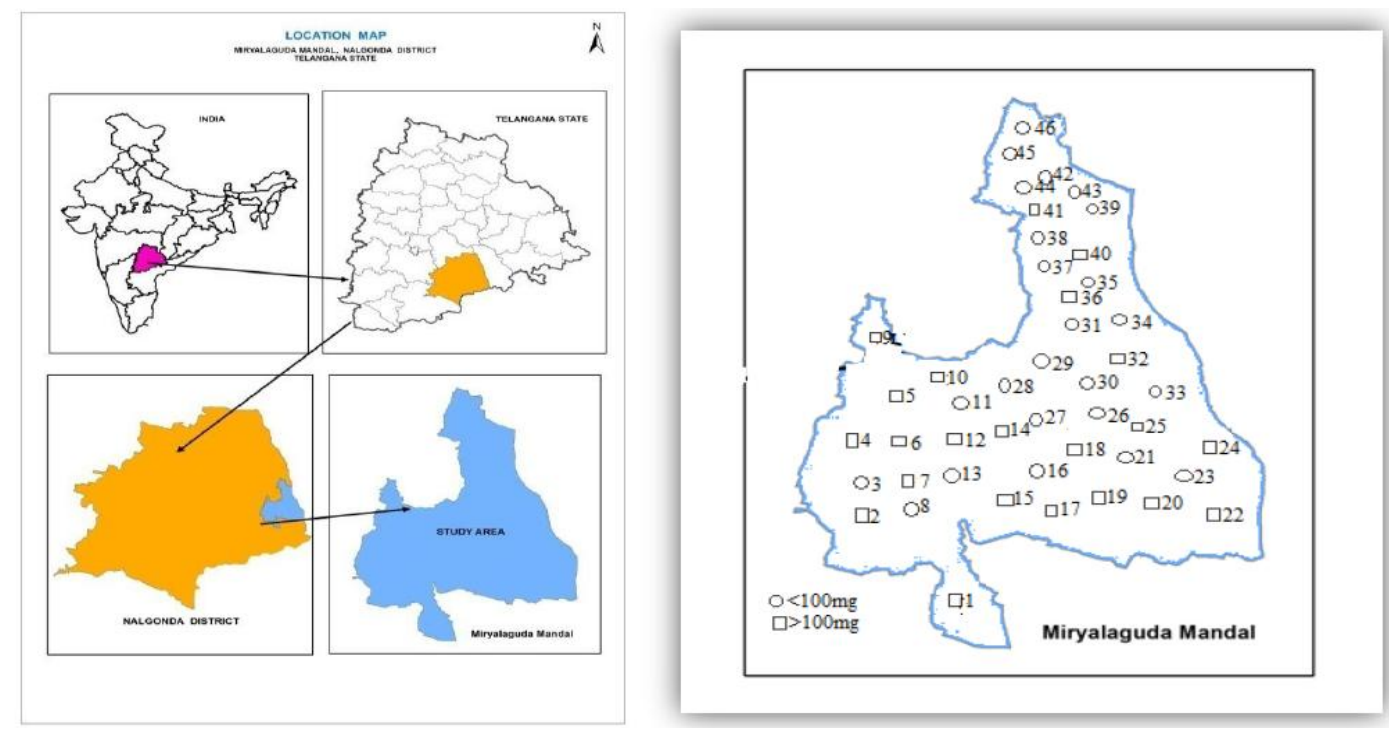

Fig.2 Extracted powder from fluoride groundwater per liter

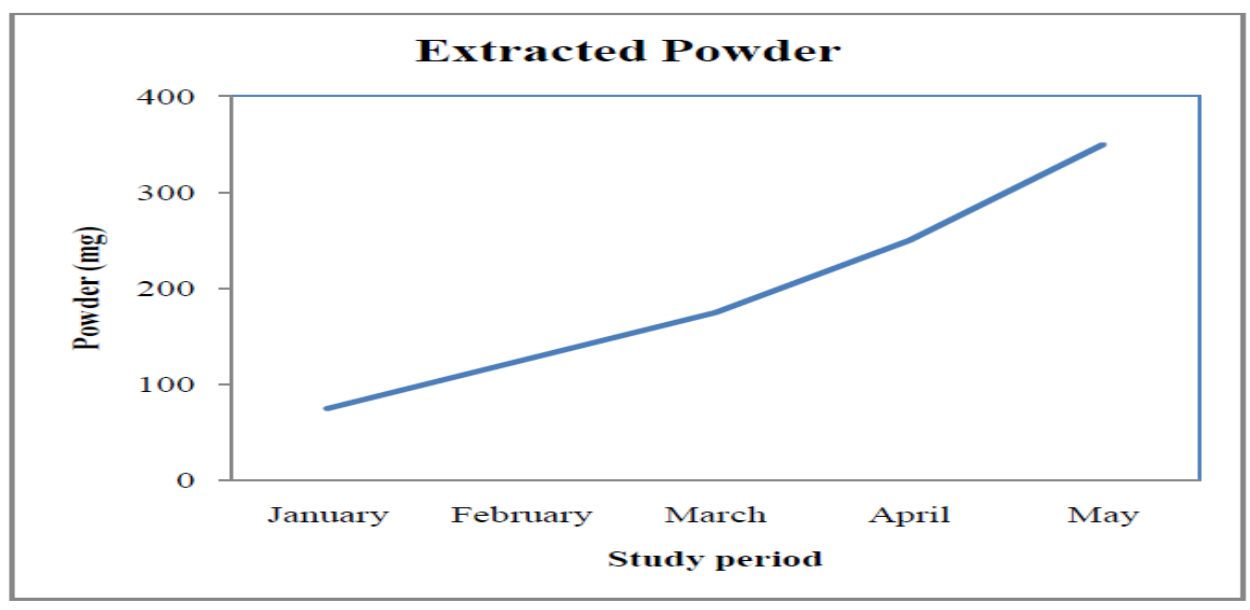


Fig.3 SEM images of extracted white powder from fluoride groundwater

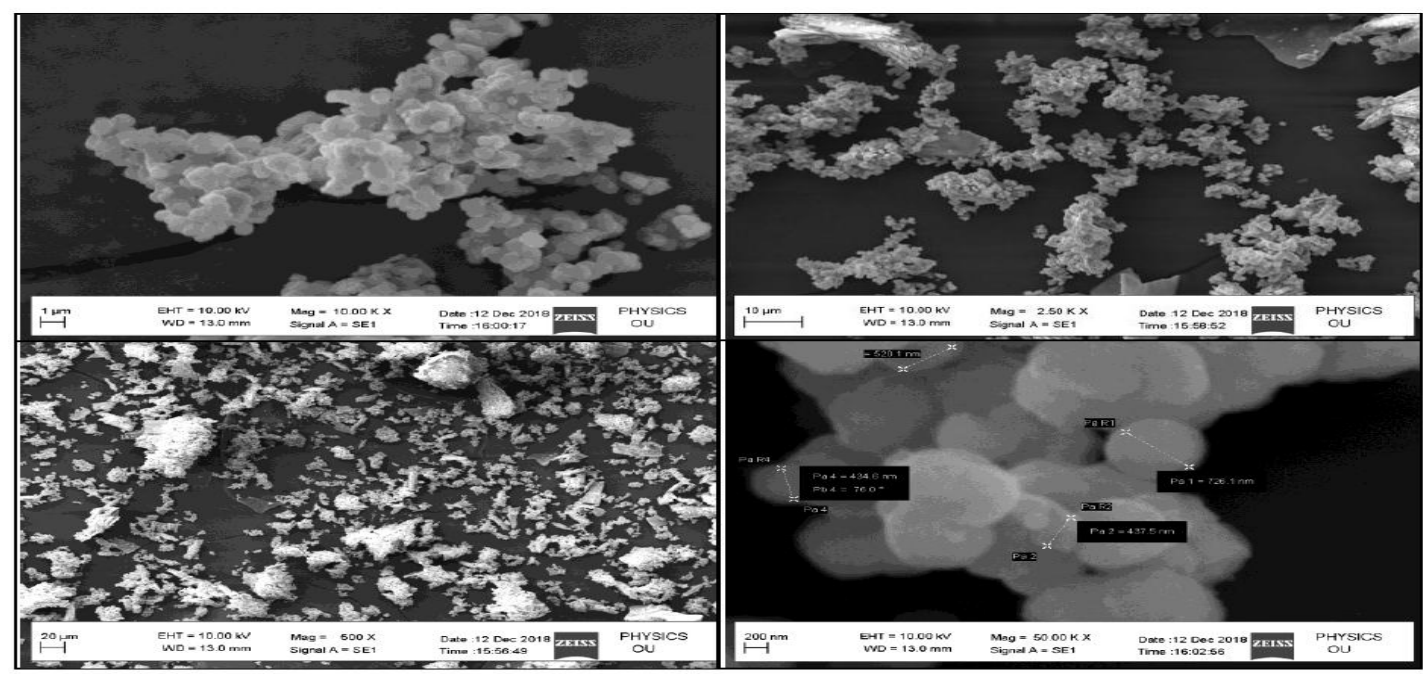

Fig.4 TEM image of extract powder from fluoride groundwater
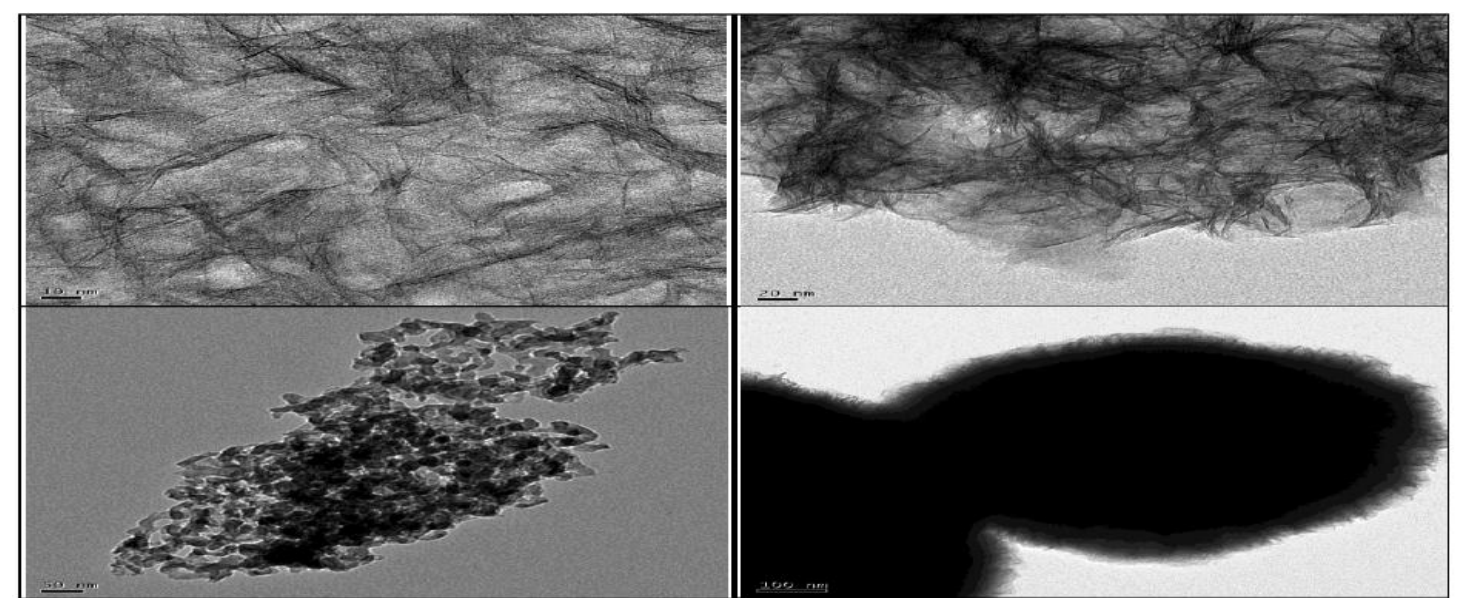

Fig.5 EDXA image of extract powder from fluoride groundwater

\begin{tabular}{|c|c|c|c|c|c|}
\hline 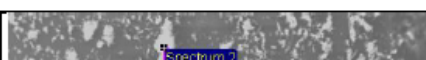 & 9 & Spettun 2 & Element & Weight $\%$ & Atomic $\%$ \\
\hline & & & O K & 50.91 & 64.30 \\
\hline & $\varphi$ & & $\mathrm{Na} \mathrm{K}$ & 6.04 & 5.31 \\
\hline & & & $\mathrm{Mg} \mathrm{K}$ & 11.49 & 9.55 \\
\hline & & & Si K & 21.36 & 15.37 \\
\hline & 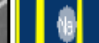 & & $\mathrm{Cl} \mathrm{K}$ & 4.95 & 2.82 \\
\hline & & & Ca K & 5.27 & 2.65 \\
\hline & & & Totals & 100.00 & \\
\hline & $\begin{array}{c}1 \\
\text { Eul Sale 1123 }\end{array}$ & $\begin{array}{llllllll}2 & 3 & 4 & 5 & 6 & 7 & 8 & \\
30 \text { arsir: } 0.000\end{array}$ & & & \\
\hline
\end{tabular}


Fig.6 XRD data from extracted white powder from fluoride groundwater at $700^{\circ} \mathrm{C}$ for $2 \mathrm{hrs}$

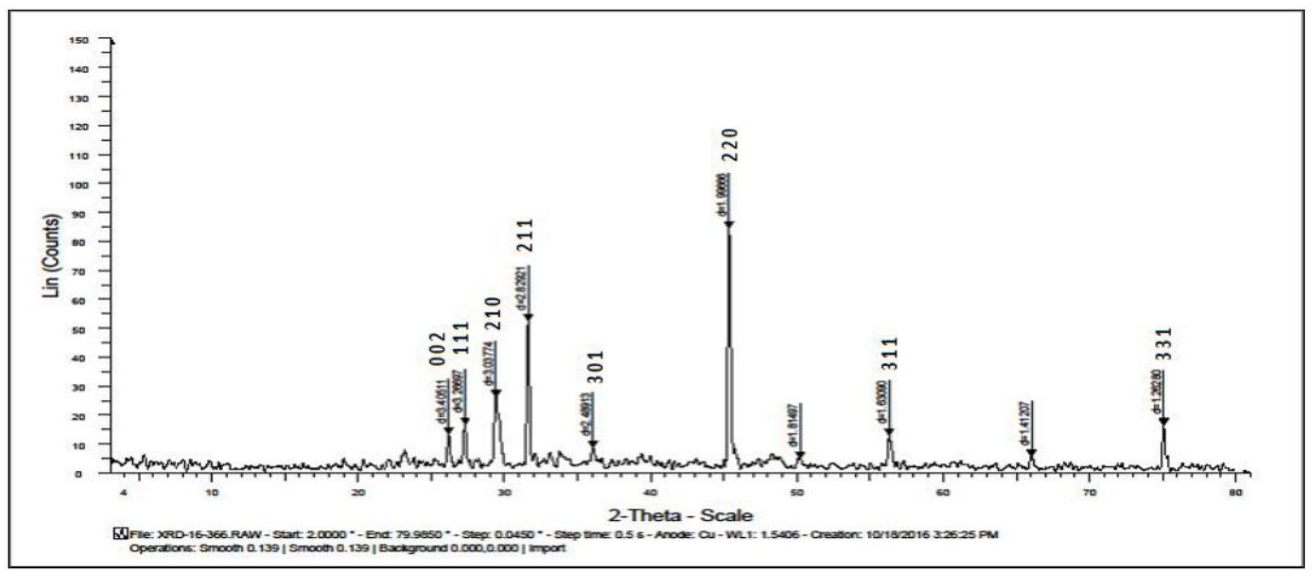

Fig.7 (A) ${ }^{31} \mathrm{P}-\mathrm{NMR}$ of $\left(\mathrm{Ca}_{5}\left(\mathrm{PO}_{4}\right)_{3} \mathrm{OH}\right)$ peak appear at $-0.251(11)$ and $(\mathrm{B}){ }^{19} \mathrm{~F}-\mathrm{NMR}$ of $\mathrm{CaF}_{2}$, white powder extract from fluoride groundwater distilled at $700^{\circ} \mathrm{C}(12)$

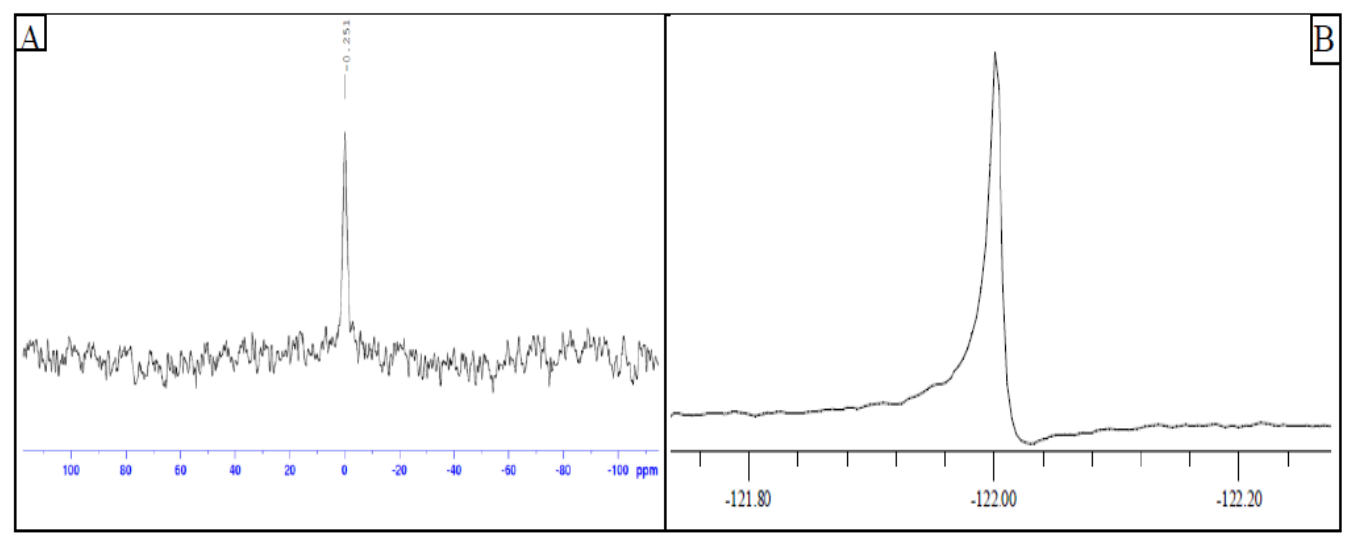

\section{X-Ray Diffraction (XRD) analysis}

$\mathrm{CaF}_{2}$ and appetite were identified by the XRD results. All the diffraction peaks can be indexed to the $\mathrm{CaF}_{2}$ cubic phase, appetite, and other components (9). Which are in agreement with the standard values for cubic $\mathrm{CaF}_{2}$ (JCPDS card number 87-0971). The displayed peaks in Fig. 6 correspond to (h $\mathrm{k} \mathrm{l})$ values of (1 111 ), ( $\left.\begin{array}{lll}2 & 2 & 0\end{array}\right),\left(\begin{array}{lll}3 & 1 & 1\end{array}\right),\left(\begin{array}{lll}4 & 0 & 0\end{array}\right)$, and (3 3 1). Appetite (h k l) values of $\left(\begin{array}{lll}0 & 0 & 2\end{array}\right)$, ( $\begin{array}{ll}2 & 1\end{array}$ 0), ( $\left.\begin{array}{lll}2 & 1 & 1\end{array}\right)$ and ( $\left.\begin{array}{lll}3 & 0 & 1\end{array}\right)$. The XRD pattern for the heated sample retained the original peaks for $\mathrm{CaF}_{2}$ and appetite, even though the sample heated for 2 hours at $700^{\circ} \mathrm{C}$.

\section{Nuclear Magnetic Resonance (NMR) analysis}

Fig. 7:(A) ${ }^{31} \mathrm{P}-\mathrm{NMR}$ of $\left(\mathrm{Ca}_{5}\left(\mathrm{PO}_{4}\right)_{3}, \mathrm{OH}\right)$ peak appear at $-0.251(11)$ and (B) ${ }^{19} \mathrm{~F}-\mathrm{NMR}$ of $\mathrm{CaF}_{2}$, white powder extract from fluoride groundwater distilled at $700^{\circ} \mathrm{C}(12)$

In conclusion the current report describes the white powder extract from fluoride groundwater characterized by XRD, SEM, TEM, ${ }^{31}$ P-NMR, and ${ }^{19}$ F-NMR. Notably, the fluoride groundwater distillation method is effective to obtained pure phase nonmaterial with shape, controllable size, and uniform morphology. The nano- $\mathrm{CaF}_{2}$, appetite were identified by the XRD. The nano- $\mathrm{CaF}_{2}$ and appetite can be used as an adequate anticaries agent in increasing the labile $\mathrm{F}$ absorption in oral fluid and thus strengthen the tooth remineralizations. Also, fluorides are established for their antimicrobial activity, 
The $\mathrm{CaF}_{2}$ nanoparticles and appetite can be used as an antimicrobial compound in several cases. Fluoride has to be the formation of rock compounds, salts; mineral ionic formation. Summer season is more fluoride level than other seasons

\section{Acknowledgments}

We gratefully acknowledge CSIR-Indian Institute of Chemical Technology (CSIRIICT), Hyderabad, India for providing financial support and KIM Division to allow IICT Communication Number for this manuscript is IICT/Pubs./2020/223.

\section{References}

1.M. Habuda-Stanić, M. Ravančić, A. Flanagan, A Review on Adsorption of Fluoride from Aqueous Solution, Materials. 7 (2014) $6317-$ 6366. https://doi.org/10.3390/ma7096317.

2. M.D.A. Bolland, D.G. Allen, Comparison of three soil tests for phosphate on lateritic soil fertilized with superphosphate, crandallite rock phosphates and apatite rock phosphates, Australian Journal of Soil Research. 25 (1987): 555-562. https://doi.org/10.1071/SR9870555.

3. R. Harder, Fluoride-Toxin or medicine, Delft, Netherlands., 2008.

4. K. Brindha, R. Rajesh, R. Murugan, L. Elango, Fluoride contamination in groundwater in parts of Nalgonda District, Andhra Pradesh, India, Environmental Monitoring and Assessment. 172 (2011): 481492. https://doi.org/10.1007/s10661-0101348-0.

5.R. Brunt, L. Vasak, J. Griffioen, Fluoride in groundwater: Probability of occurrence of excessive concentration on global scale, International Groundwater Resources Assessment Centre, UNESCO. Report nr. (2004) 20p.

6. B.G. Survey, BGS. 2009. Water quality fact sheet: Fluoride, 2009.

7. P. Mamatha, S.M. Rao, W.B. Apambire, D.R. Boyle, F.A. Michel, N.2010. Environmental Geology. (5)2: 131-142. https://doi.org/10.1007/s002540050221.

8. Y.N. Yang, X.L. Zhu, X.Z. Kong, Controls of crystal morphology, size and structure in spontaneous precipitation of calcium carbonate, Wuji Cailiao Xuebao/Journal of Inorganic Materials. 28 (2013): 1313-1320. https://doi.org/10.3724/SP.J.1077.2013.13163.

9. N.D. Alharbi, Size controlled CaFnanocubes and their dosimetric properties using photoluminescence technique, Journal of Nanomaterials. $2015 \quad$ (2015). https://doi.org/10.1155/2015/136957.

10. T. Freeman, A. Thind, M. Stewart, J. Brown, E. Vingilis, Research Paper, Healthcare Policy | Politiques de Santé. 5 (2009): e187-e206. https://doi.org/10.12927/hcpol.2013.21181.

11.R. Mathew, P.N. Gunawidjaja, I. IzquierdoBarba, K. Jansson, A. García, D. Arcos, M. Vallet-Regí, M. Edén, Solid-state 31P and 1H NMR investigations of amorphous and crystalline calcium phosphates grown biomimetically from a mesoporous bioactive glass, Journal of Physical Chemistry C. 115 (2011): 20572-20582. https://doi.org/10.1021/jp206237n.

12.P. Jain, S. Kim, R.E. Youngman, S. Sen, Direct Observation of Defect Dynamics in Nanocrystalline CaF2: Results from 19F MAS NMR Spectroscopy, Journal of Physical Chemistry Letters. 1 (2010): 1126-1129. https://doi.org/10.1021/jz100152j.

\section{How to cite this article:}

Valipenta Narasimhulu, Sudhakar Bansod, Lakshmi Srinivasa Rao Kundeti and Ravindra M. Kumbhare. 2020. Characterization of Raw Material Powder Extracted at High Temperature from Fluoride Groundwater. Int.J.Curr.Microbiol.App.Sci. 9(09): 2989-2994. doi: https://doi.org/10.20546/ijcmas.2020.909.368 